\title{
The Effect of Cultural Intelligence and Creative Thinking on the Practical Technical Capabilities of Trabzon University Physical Education Students
}

\author{
Elif Aydin \\ Faculty of Physical Education and Sport Sciences, Gumuhshaneh University, Turkey. \\ Email:aydinelif6129@gmail.com Tel:00905302659515
}

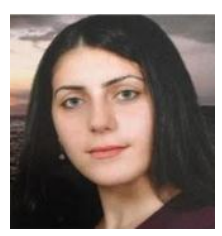

\begin{abstract}
The purpose of this research was to investigate the effect of cultural intelligence and creative thinking on the practical technical capabilities of Trabzon University Physical Education Students. In order to measure the cultural intelligence, creative thinking and technical capabilities in sport, the Standard questionnaires of Early and Ang (2003), Torrance (2000) and Behringer et al. (2011) were used respectively. Cronbach's alpha coefficient for the cultural intelligence, creative thinking and technical capability questionnaires were $0.79,0.8$, and 0.85 , respectively. Questionnaires were distributed to 120 students, (40 for football, 40 for volleyball and 40 for badminton classes). The findings showed that cultural intelligence and creative thinking have a significant positive effect on the technical capabilities of Trabzon University Physical Education students in all three football lessons (foot technical capability), volleyball and badminton (hand technical capability). Also, cultural intelligence and creative thinking have a significant positive effect on the technical capabilities of football classes (foot technical capability). Cultural intelligence and creative thinking have a significant positive effect on the technical capabilities of students in volleyball classes (hand technical abilities). Cultural intelligence and creative thinking have a significant positive effect on the technical capabilities of badminton classes (hand technical ability). Finally, it can be said that cultural intelligence and creative thinking have a significant positive effect on the practical technical capabilities of physical education students of Trabzon University participating in practical lessons (football, volleyball and badminton) both simultaneously and separately in each classroom.
\end{abstract}

Keywords: Cultural intelligence, Creative thinking, Technical capacity.

Citation | Elif Aydin (2019). The Effect of Cultural Intelligence and Creative Thinking on the Practical Technical Capabilities of Trabzon University Physical Education Students. Asian Journal of Education and Training, 5(2): 392-396.

History:

Received: 2 April 2019

Revised: 8 May 2019

Accepted: 17 June 2019

Published: 15 August 2019

Licensed: This work is licensed under a Creative Commons

Attribution 3.0 License (oc) EY

Publisher: Asian Online Journal Publishing Group
Funding: This study received no specific financial support.

Competing Interests: The author declares that there are no conflicts of interests regarding the publication of this paper.

Transparency: The author confirms that the manuscript is an honest, accurate, and transparent account of the study was reported; that no vital features of the study have been omitted; and that any discrepancies from the study as planned have been explained.

Ethical: This study follows all ethical practices during writing.

\section{Contents}

1. Introduction

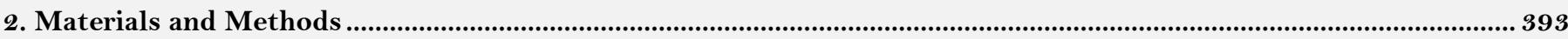

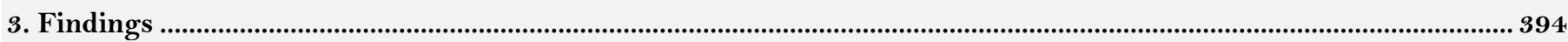

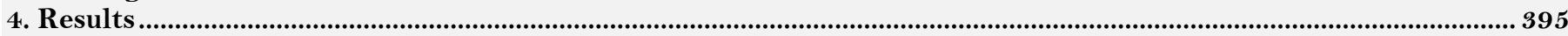

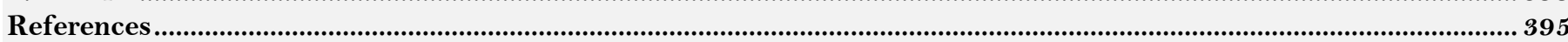




\section{Contribution of this paper to the literature}

This study contributes to the existing literature by investigating the effect of cultural intelligence and creative thinking on the practical technical capabilities of Trabzon University Physical Education Students.

\section{Introduction}

Practical technical abilities in sport are not stable features and are reinforced by training and exercises (Dolores et al., 2018). However, the presence of psychological and personality components can affect the practical technical capabilities in sport (Charbonneau et al., 2001). Practical technical abilities in sport are one of the most important factors affecting the performance of individuals, especially physical education students (Gede and Hubbard, 2014). The presence of athletes or students with high technical abilities in the use of hands in sports such as volleyball and badminton, as well as high technical abilities in the use of foot in sports such as football, has dramatically increased the performance of individuals as well as their sporting and educational achievements.

Practical technical capabilities in sport are the potential or actual power of an individual to perform a sporting activity. Technical abilities of sports are knowledge and the ability to perform certain actions in a physical exercise that requires full mastery of the use of special techniques and tools and practical competence in those actions. In technical abilities, the athlete is on a daily basis gaining experience, learning, learning, and at the same time experiencing and moving towards excellence (Charbonneau et al., 2001). Technical abilities in sports, and in particular, the skill in using hands and feet in various sports, are the underlying foundations of the growth and success of learning the principles of physical education and or the success of professional sport (Wang et al., 2005). Therefore, it is important to address the factors that influence these capabilities and find them. In addition to correct training, exercise, and physical conditions and characteristics of individuals, the presence of psychological and personality components can affect the capabilities mentioned and enhance and enhance it (Gede and Hubbard, 2014). Among these factors are cultural intelligence and creative thinking in individuals and especially students. Cultural intelligence is an exuberant of intelligence that has a great deal to do with a diverse cultural environment. Cultural intelligence can be defined as the ability to apply skills and abilities in different environments (Dolores et al., 2018). Statistics show that many failures of people in various social, educational and even occupational contexts occur when people do not understand the different cultures ruling different groups (Andrea et al., 2018). There are a variety of cultures and even subcultures within a national culture of a wide range of emotions and emotions (Imran and Murad, 2018). In such a way that differences in language, ethnicity, politics, and many other characteristics, including differences in the various media settings, including the cultural environment of universities for physical education students and their differences with other social and sports spaces, can emerge as potential sources of conflict, and In the absence of a proper understanding, the development of appropriate relationships would be difficult (Hu et al., 2018). Creative thinking is also one of the skills that promotes the growth of individuals and the whole society (Almajali, 2009). As human societies have so far been hijacked by those who have been able to discover the inventions and discoveries that have made it easier for them to make life easier (MacDonald and Bigelow, 2010).

Cultural intelligence, the ability of individuals to grow their own lives through the continuity of learning, better understanding of customs, and different values and effective behavior with people with cultural backgrounds and perceptions. Cultural intelligence is a new domain of intelligence that has a lot to do with diverse work environments (Imran and Murad, 2018). Some aspects of culture can be easily seen. The obvious factors such as art, music, and behavioral styles are the following. But most of the challenging sections of culture are hidden. Opinions, values, expectations, attitudes and assumptions are elements of culture that are not seen but affect the behavior of individuals. Cultural intelligence allows people to recognize how others think and how they respond to behavioral patterns, thereby reducing intercultural communication barriers and empowering individuals to manage cultural diversity (Dolores et al., 2018). The use of creative thinking, even in everyday life, including sporting and educational activities, can provide innovative and innovative methods and solutions for solving existing problems and stereotyping issues (Sindane, 2011) and Strengthening people's capacities for better performance (Matthews, 2011). Because students have creative thinking, innovative ways to enhance the ability and ability to use hand and foot in sporting activities in different disciplines will have a sport (Brink, 2004).

On the other hand, creative thinking is a skill that a person has from combining problem-solving skills and decision-making from new thoughts or relationships, and finds the power to discover and select new solutions. In other words, the art of breaking daily routines is called creative thinking. Creativity can be considered as the highest capacity for the final thought and thought of man (Sindane, 2011).

Therefore, this research seeks to investigate the effect of cultural intelligence and creative thinking on the technical capabilities of physical education students at Trabzon University, including the potential of using hands and feet in sports and volleyball, badminton and football.

\section{Materials and Methods}

The present research is applied in terms of the purpose of the research, in terms of method, descriptive and correlation. Therefore, in terms of data collection method, the research method is a survey strategy. The statistical population of this study is Trabzon University of Physical Education students who are attending practical sports lessons including volleyball lessons, badminton, and soccer. Therefore, 40 students (out of a total of 120 students) from each class were selected as the statistical sample for this research. In order to measure the cultural intelligence variable, the Standard questionnaire (Early and Ang, 2003) Standard questionnaire (Torrance, 2000) for measuring the variables of creative thinking, and also for measuring the variables of technical capabilities in sport, were used by standard questionnaire (Behringer et al., 2011). Cronbach's Alpha coefficient for the CQI was 0.79 , for creative thinking questionnaire equal to 0.8 , and also for the practical technical capability questionnaire in sport was 0.85 . For statistical analysis of the research data, SPSS 20 software and the "multivariate regression" test have been used. 


\section{Findings}

Table-1. Study of the effect of cultural intelligence and creative thinking on practical technical capabilities (for all three football, volleyball and badminton lessons) Trabzon University Physical Education students.

\begin{tabular}{l|c|c|c|c|c|c}
\hline \multicolumn{2}{c}{ Coefficients $^{\mathbf{a}}$} \\
\hline \multirow{2}{*}{ Model } & \multicolumn{2}{c}{ Unstandardized Coefficients } & Standardized Coefficients & \multirow{2}{*}{ t } & \multirow{2}{*}{ Sig. } \\
\cline { 3 - 6 } \multicolumn{2}{c|}{} & B & Std. Error & Beta & -1.978 & .050 \\
\hline \multirow{3}{*}{1} & Constant) & -.564 & .285 & & 6.831 & .000 \\
\cline { 2 - 6 } & Cultural Intelligence & .594 & .087 & .478 & .384 & .000 \\
\cline { 2 - 6 } & Creative Thinking & .522 & .095 & .480 & .000 \\
\hline
\end{tabular}

a. Dependent Variable: Practical technical capability.

According to the results of Table 1 (considering the significant level of test error, sig. Or p, which is less than 0.05 for both "Cultural Intelligence" and "Creative Thinking" variables), and considering the beta coefficients, the highest power The prediction with the coefficient of 0.478 is related to the "cultural intelligence" variable, and then the "creative thinking" variable with a beta coefficient of 0.384 is located, which has the technical capabilities of Trabzon University Physical Education students in all three football lessons Technical foot exercises), volleyball and badminton (technical capability of hand use). It can be concluded that the "cultural intelligence" variable affects and improves the "creative thinking" variable on the practical technical capabilities of Trabzon University Physical Education students.

Table-2. Investigating the effect of cultural intelligence and creative thinking on the practical technical capabilities of foot use (for football lessons) Trabzon University Physical Education students.

\begin{tabular}{|c|c|c|c|c|c|c|}
\hline \multicolumn{7}{|c|}{ Coefficients $^{a}$} \\
\hline & \multirow{2}{*}{ Model } & \multicolumn{2}{|c|}{ Unstandardized Coefficients } & \multirow{2}{*}{\begin{tabular}{|c|} 
Standardized Coefficients \\
Beta \\
\end{tabular}} & \multirow{2}{*}{$\mathbf{t}$} & \multirow{2}{*}{ Sig. } \\
\hline & & B & Std. Error & & & \\
\hline \multirow{3}{*}{1} & $($ Constant $)$ & .171 & .466 & & .368 & .715 \\
\hline & Cultural Intelligence & .539 & .132 & .508 & 4.069 & .000 \\
\hline & Creative Thinking & .369 & .134 & .343 & 2.745 & .009 \\
\hline
\end{tabular}

a. Dependent Variable: Practical technical capability.

According to the results of Table 2 (considering the significant level of test error, sig. Or p, which is less than 0.05 for both "Cultural Intelligence" and "Creative Thinking" variables), and considering the beta coefficients, the highest power The prediction with the coefficient of 0.508 is related to the "cultural intelligence" variable, followed by the "creative thinking" variable with a beta coefficient of 0.343 , which incorporates the practical technical capabilities of foot use in Trabzon's student physical education students at the lesson Football Forecast. It can be concluded that the "cultural intelligence" variable affects and improves the "Cultural Intelligence" variable slightly more than the "creative thinking" variable on the practical technical capabilities of foot use in physical education students participating in the practical course of the University of Trabzon University. So that if cultural intelligence and creative thinking are increased in Trabzon's Physical Education students, their practical technical capabilities in using sports footwear will improve in sporting activities.

Table-3. Study of the effect of cultural intelligence and creative thinking on the practical technical abilities of hand use (for volleyball lessons) of Trabzon University Physical Education students.

\begin{tabular}{|c|c|c|c|c|c|c|}
\hline \multicolumn{7}{|c|}{ Coefficients $^{\mathrm{a}}$} \\
\hline & \multirow{2}{*}{ Model } & \multicolumn{2}{|c|}{ Unstandardized Coefficients } & \multirow{2}{*}{$\begin{array}{c}\text { Standardized Coefficients } \\
\text { Beta }\end{array}$} & \multirow{2}{*}{$\mathbf{t}$} & \multirow{2}{*}{ Sig. } \\
\hline & & B & Std. Error & & & \\
\hline \multirow{3}{*}{1} & (Constant) & -.980 & .583 & & -1.679 & .102 \\
\hline & Cultural Intelligence & .613 & .164 & .464 & 3.743 & .001 \\
\hline & Creative Thinking & .564 & .175 & .399 & 3.220 & .003 \\
\hline
\end{tabular}

a. Dependent Variable: Practical technical capability

According to the results of Table 3 (considering the significant level of test error, sig. Or p, which is less than 0.05 for both "Cultural Intelligence" and "Creative Thinking" variables), and considering the beta coefficients, the highest power The prediction with the coefficient of 0.464 is related to the variable "cultural intelligence" and then the "creative thinking" variable with the beta coefficient of 0.399 is located, which utilizes the practical technical capabilities of hand use in Trabzon's student physical education students in the lesson Volleyball predict. It can be concluded that the "cultural intelligence" variable affects and improves the "cultural intelligence" variable slightly more than the "creative thinking" variable on the practical capabilities of hands-on use in physical education students participating in the volunteer practice course of Trabzon University. So that if Cultural Intelligence and Creative Thinking Increase in Trabzon Students' Physical Education, their practical technical abilities will improve on volleyball.

Table-4. Investigating the impact of cultural intelligence and creative thinking on the practical handle-handle technical abilities (for badminton lessons) Trabzon University Physical Education students.

\begin{tabular}{|c|c|c|c|c|c|c|}
\hline \multicolumn{7}{|c|}{ Coefficients $^{\mathrm{a}}$} \\
\hline & \multirow{2}{*}{ Model } & \multicolumn{2}{|c|}{ Unstandardized Coefficients } & \multirow{2}{*}{$\begin{array}{c}\text { Standardized Coefficients } \\
\text { Beta }\end{array}$} & \multirow{2}{*}{$\mathbf{t}$} & \multirow{2}{*}{ Sig. } \\
\hline & & B & Std. Error & & & \\
\hline \multirow{3}{*}{1} & $($ Constant $)$ & -.298 & .419 & & -.711 & .482 \\
\hline & Cultural Intelligence & .515 & .157 & .457 & 3.272 & .002 \\
\hline & Creative Thinking & .564 & .197 & .400 & 2.866 & .007 \\
\hline
\end{tabular}

a. Dependent Variable: Practical technical capability. 
According to the results of Table 4 (considering the significant level of test error, sig. Or p, which is less than 0.05 for both "Cultural Intelligence" and "Creative Thinking" variables), and considering the beta coefficients, the highest power The prediction with the coefficient of 0.457 is related to the "cultural intelligence" variable, and then the "creative thinking" variable with a beta coefficient of 0.4 lies with the technical capabilities of hands-on use in Trabzon's student physical education students in the lesson Badminton predict It can be concluded that the variable "Cultural Intelligence" affects and improves on the "creative thinking" variable on the practical skills of using hands in physical education students participating in the practical course of the Badminton University of Trabzon. So that if Cultural Intelligence and Creative Thinking Increase in Trabzon's Physical Education Students, their practical technical abilities in using hand in badminton sports will improve.

\section{Results}

In this research, the effect of cultural intelligence and creative thinking on the practical technical abilities of Trabzon University students was studied.

- The results showed that cultural intelligence and creative thinking have a significant positive effect on technical abilities of physical education students of Trabzon University (meaningful level of test error, sig. Or p for both variables "Cultural Intelligence" and "Creative Thinking" less). From 0.05) Considering the beta coefficients, it can be said that the highest predictive power with the coefficient of 0.478 relates to the variable "cultural intelligence" and then the variable "creative thinking" with a beta coefficient of 0.384 , which has practical technical capabilities of Trabzon University Physical Education students simultaneously predict at the same time in all three football lessons (foot wear technical capability), volleyball and badminton (technical use of hand). It could be concluded that the variable "cultural intelligence" affects and improves the "creative thinking" variable on the practical technical capabilities of Trabzon University Physical Education students. The results of this section were consistent with the research by Andrea et al. (2018) and Sindane (2011).

- In the case of physical education students participating in a practical football lesson, the results showed that the highest predictive power with a coefficient of 0.508 is related to the cultural intelligence variable, followed by the variable "creative thinking" with a beta coefficient of 0.343 Which predicts the practical technical possibilities of using foot in Trabzon University Physical Education students in a football lesson (meaningful level of test error, sig. Or p for both variables Cultural Intelligence and Creative Thinking less than 0.05 It was concluded that the "cultural intelligence" variable affects and improves the "Cultural Intelligence" variable slightly more than the "creative thinking" variable on the practical technical capabilities of using foot in the physical education students participating in the practical Education of the University of Trabzon University. The results of this section were aligned with Christian et al. (2017); Imran and Murad (2018) and Brink (2004).

- In the case of physical education students participating in volleyball practical training, the results showed that the highest predictive power with the 0.464 beta coefficient is related to the cultural intelligence variable, followed by the variable "creative thinking" with a beta coefficient of 0.399 Which predicts the practical skills of using hand in Trabzon University Physical Education students in volleyball lessons (the significance level of test error, sig. Or p for both variables Cultural Intelligence and Creative Thinking is less than 0.05. It can be concluded that the "cultural intelligence" variable affects and improves the "cultural intelligence" variable slightly more than the "creative thinking" variable on the practical capabilities of hands-on use in physical education students participating in the volunteer practice course of Trabzon University. The results of this section were consistent with Wang et al. (2005) and Christian et al. (2017).

Also, in the case of physical education students participating in the practical lesson of badminton, the results showed that the highest predictive power with the coefficient of 0.457 is related to the variable "cultural intelligence" and then the variable "creative thinking" with a beta coefficient of 0.4 Which predicts practical handheld technical abilities in Trabzon University Physical Education Students in badminton lessons.

Finally, it can be said that Cultural Intelligence and Creative Thinking had a significant positive effect on the technical and practical capabilities of physical education students of Trabzon University participating in the practical lessons (football, volleyball and badminton) and also separately among the participating students. All three practical lessons included Cultural Intelligence and Creative Thinking had a significant positive effect on students' technical skills.

\section{References}

Almajali, H.K., 2009. The influence of family upbringing style and locus of control on the creative thinking of preparatory school learners in the United Arab Emirates. Unpublished Doctoral Dissertation, University of South Africa.

Andrea, C., O.B. Ayoko and N. Amoo, 2018. The moderating role of cultural intelligence in the relationship between cultural orientations and conflict management styles. Journal of Business Research, 89: 10-20.Available at: https://doi.org/10.1016/j.jbusres.2018.03.042.

Behringer, M., A. vom Heede, M. Matthews and J. Mester, 2011. Effects of strength training on motor performance skills in children and adolescents: A meta-analysis. Pediatric Exercise Science, 23(2): 186-206.Available at: https://doi.org/10.1123/pes.23.2.186.

Brink, N.H., 2004. Locus of control and creativity in late middle childhood. Potchefstroom: North-West University.

Charbonneau, D., J. Barling and E.K. Kelloway, 2001. Transformational leadership and sports performance: The mediating role of intrinsic motivation. Journal of Applied Social Psychology, 31(7): 1521-1534.Available at: https://doi.org/10.1111/j.15591816.2001.tbo2686.x.

Christian, S., L. Crust and S.A. Vella, 2017. New directions in the psychology of optimal performance in sport: Flow and clutch states. Current Opinion in Psychology, 16: 48-53.

Dolores, F.-J.M., C.M. Sabiote-Ortiz, J.D. Martín-Santana and A. Beerli-Palacio, 2018. Antecedents and consequences of cultural intelligence in tourism. Journal of Destination Marketing \& Management, 8: 350-358.Available at: https://doi.org/10.1016/j.jdmm.2017.07.006.

Early, P.C. and S. Ang, 2003. Cultural intelligence, individual interaction across culture. England: Stanford Business Books.

Gede, G. and M. Hubbard, 2014. A bioenergetic model for simulating athletic performance of intermediate duration. Journal of Biomechanics, 47(14): 3448-3453.Available at: https://doi.org/10.1016/j.jbiomech.2014.09.017.

Hu, S., H. Liu and J. Gu, 2018. What role does self-efficacy play in developing cultural intelligence from social media usage? Electronic Commerce Research and Applications, 28: 172-180.Available at: https://doi.org/10.1016/j.elerap.2018.01.009.

Imran, A. and A. Murad, 2018. The role of knowledge spillovers and cultural intelligence in enhancing expatriate employees' individual and team creativity. Journal of Business Research, 101: 561-573. 
MacDonald, N.M. and S. Bigelow, 2010. Teaching for creativity through fashion design. Journal of Family and Consumer Sciences, 102(2): 48-53.

Matthews, M.L., 2011. Connecting creativity and critical thinking to the campaign planning process. Communication Teacher, 25(1): 6167.Available at: https://doi.org/10.1080/17404622.2010.527299.

Sindane, L.M., 2011. The relationship between happiness, creativity, personality and locus of control in ireland for those who are employed and unemployed. Irland: Publisher: Dublin Business School.

Torrance, E.P., 2000. Research review for the torrance tests of creative thinking fig-uraland verbalforms a and b. Bensenville, IL: Scholastic Testing Services.

Wang, C., W. Liu, S.J. Biddle and C.M. Spray, 2005. Cross-cultural validation of the conceptions of the nature of athletic ability questionnaire version 2. Personality and Individual Differences, 38(6): 1245-1256.Available at: https://doi.org/10.1016/j.paid.2004.08.007. 